\title{
Viscosity of partially hydrolyzed polyacrylamide under shearing and heat
}

\author{
Changhong Gao
}

Received: 26 November 2012 / Accepted: 28 January 2013/Published online: 12 February 2013

(C) The Author(s) 2013. This article is published with open access at Springerlink.com

\begin{abstract}
Polymer flooding is the most successful chemical method to enhance oil recovery. This technique has achieved large-scale field application in China. Polymer flooding is also being tested in several heavy oil fields. For oil field applications, partially hydrolyzed polyacrylamide (HPAM) is the most widely used polymer. HPAM must maintain high viscosity to achieve good oil recovery. In reality, however, polymers can be severely degraded by shearing and heat in the underground environment. This phenomenon is studied in this paper. The two HPAM test samples have molecular weight of 10 million and 20 million. The samples were added to water to achieve concentrations of 500 to $3,000 \mathrm{ppm}$. The first group of tests was conducted to study the effect of shearing on HPAM viscosity. The second group of tests was carried out to evaluate the effect of high temperature up to $90{ }^{\circ} \mathrm{C}$ on HPAM viscosity. It was discovered that both shearing and high temperature can severely reduce polymer viscosity. Data analysis shows that the empirical power law parameters are strong functions of polymer concentration and temperature. Simple formulas are proposed to correlate HPAM viscosity with shearing rate, polymer concentration and temperature. These formulas are useful tools for predicting HPAM viscosity in field applications.
\end{abstract}

Keywords HPAM · Viscosity · Shearing strain · Degradation · Power law

C. Gao $(\bowtie)$

Sinopec Shengli Oil Field Company, Dongying, China

e-mail: 237184689@qq.com

\section{Introduction}

During oil production, water is often injected into reservoirs to sweep oil into the production well. Because oil viscosity can be much higher than water viscosity, injected water moves faster than oil, leaving oil behind. This phenomenon is referred to as viscous fingering. Polymer can be added to the injected water to retard viscous fingering. Polymer increases the viscosity of injected water, reduces water mobility, and therefore achieves a more stable displacement (Littmann 1988).

Polymer flooding has become the most successful chemical method for enhanced oil recovery (EOR). For the Daqing oil field in China, polymer flooding has contributed to more than $10 \%$ of enhanced oil recovery (Wang et al. 2009). This technology is also being tested in heavy oil fields (Gao 2011). For field applications, partially hydrolyzed polyacrylamide (HPAM) is the most widely used polymer, due to its relatively cheap price and good solubility in water. The molecular structure of HPAM is given in Fig. 1 (Sheng 2010).

Polymer solution is a non-Newtonian fluid that follows the power law given in Eq. 1, where $\mu$ is the viscosity $\left(C_{\mathrm{p}}\right)$, $\gamma$ is the shear rate $(1 / \mathrm{s}), k$ is the consistency index, and $n$ is the flow behavior index (Rabia 1985). If the power law parameters $(k$ and $n)$ can be determined, then the polymer solution viscosity is easily calculated under any shear rate.

$\mu=k \gamma^{n}$

Polymer solution must maintain high viscosity to mobilize oil in reservoir. However, polymer often suffers from viscosity loss due to shearing, heat and salinity that exist in wellbore and reservoir (Gao 2011). HPAM degradation has been studied for many years. In the 1970s, it was concluded that shearing largely depresses 


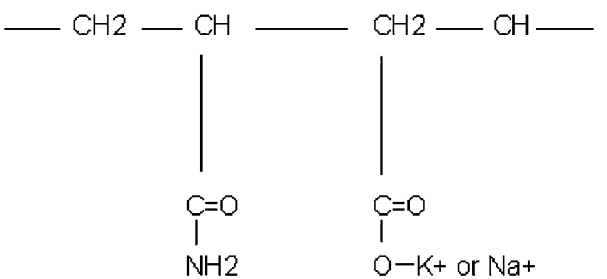

Fig. 1 Structure of HPAM

HPAM viscosity (Mungan 1972; Maerker 1975). But in a recent article, some researchers argue that shearing has a very slight effect on flow of HPAM in real reservoir (Seright et al. 2011). A study on temperature effect demonstrated that HPAM is stable up to $90{ }^{\circ} \mathrm{C}$ in fresh water (Ryles 1988). In China, a polymer flooding project with HPAM proved successful in a reservoir whose temperature was at $75^{\circ} \mathrm{C}$ (Chen et al. 1998). Salinity also greatly impacts HPAM viscosity (Needham and Doe 1987; Ward and Martin 1981), but the salinity effect is not covered in this paper.

Unfortunately, it is still a challenge to correctly predict the viscosity of HPAM under shearing and thermal degradation. This paper studies these phenomena through laboratory testing and builds correlations for viscosity of HPAM solution. This work can improve the understanding of flow of polymer solution in underground environment.

\section{Materials and methods}

Two HPAM samples, coded as 3,100 and 3,200, were supplied by a polymer producer in the form of powders. The molecular weight of product 3,100 was around 10 million, and that of product 3,200 was 20 million. For both products, the degree of hydrolysis was around $25 \%$. Polymer powder was added to distilled water and stirred for $48 \mathrm{~h}$ to ensure good mixing.

The first group of tests was conducted to study the effect of shear rates on polymer viscosity. The tested polymer concentrations ranged from 500 to $3,000 \mathrm{ppm}$. The shear rates ranged from 1 to $1,000 \mathrm{~s}^{-1}$. All tests were conducted at the relatively low temperature of $30^{\circ} \mathrm{C}$. The second group of tests was conducted to study the effect of high temperature on polymer viscosity. The test temperature was controlled at 50, 70 and $90{ }^{\circ} \mathrm{C}$. The shear rate was controlled at $1,10,100$ and $1,000 \mathrm{~s}^{-1}$. The tested polymer concentration was $1,500 \mathrm{ppm}$.

All viscosity measurements were conducted by a torquetype viscometer. During tests, strain was forced by a motor and the generated torque was detected by transducer. The device could measure shear rates ranging from 0.1 to $1000 \mathrm{~s}^{-1}$. The temperature was controlled by a circulator.

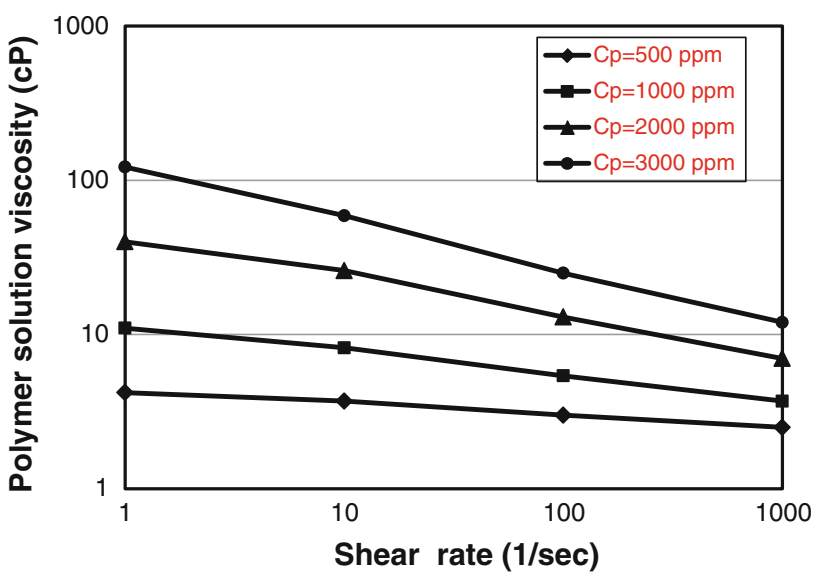

Fig. 2 Viscosity data at different polymer concentrations

\section{Experimental results}

The viscosity data for the product 3,100 at $30{ }^{\circ} \mathrm{C}$ are given in Fig. 2. The trend clearly complies with the power law. Similar test results were obtained for the product 3,200. It is obvious that higher HPAM concentration leads to higher viscosity. It can also be concluded that polymer viscosity is reduced at higher shear rate.

The test results for the product 3,100 at elevated temperatures are given in Fig. 3. The trends are close to power law relationship. Similar test results were obtained for the product 3,200. It can be seen that polymer viscosity decreases at higher temperature.

\section{Discussions}

In this section, effort is spent on studying the numerical relations between the power law parameters, polymer concentration and temperature. Based on the test data, the power law parameters ( $k$ and $n$ ) can be obtained via curve fitting. For the first group of tests, the temperature was

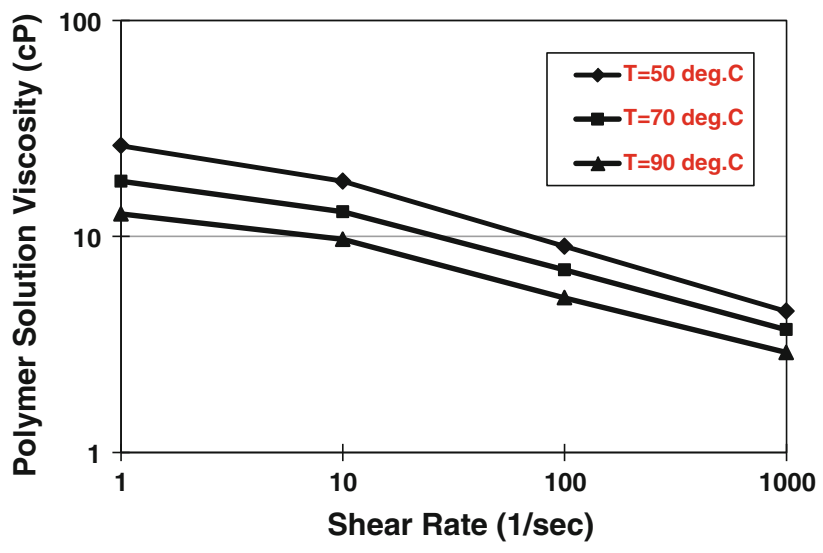

Fig. 3 Effect of temperature on polymer viscosity 
Table 1 Power law parameters for the first group of tests

\begin{tabular}{lllrl}
\hline $\begin{array}{l}\text { Polymer } \\
\text { product }\end{array}$ & $\begin{array}{l}\text { Polymer } \\
\text { concentration }(\mathrm{ppm})\end{array}$ & $\begin{array}{l}\text { Temperature } \\
\left({ }^{\circ} \mathrm{C}\right)\end{array}$ & $k$ & \multicolumn{1}{l}{$n$} \\
\hline 3,100 & 500 & 30 & 4.28 & -0.077 \\
& 1,000 & & 11.33 & -0.160 \\
& 2,000 & & 42.64 & -0.257 \\
& 3,000 & & 123.81 & -0.339 \\
3,200 & 500 & 30 & 6.45 & -0.123 \\
& 1,000 & & 24.35 & -0.244 \\
& 2,000 & & 103.20 & -0.390 \\
& 3,000 & & 275.94 & -0.480 \\
\hline
\end{tabular}

Table 2 Power law parameters for the second group of tests

\begin{tabular}{|c|c|c|c|c|}
\hline $\begin{array}{l}\text { Polymer } \\
\text { product }\end{array}$ & $\begin{array}{l}\text { Polymer } \\
\text { concentration (ppm) }\end{array}$ & $\begin{array}{l}\text { Temperature } \\
\left({ }^{\circ} \mathrm{C}\right)\end{array}$ & $k$ & $n$ \\
\hline \multirow[t]{3}{*}{3,100} & 1,500 & 50 & 28.90 & -0.260 \\
\hline & & 70 & 19.00 & -0.233 \\
\hline & & 90 & 14.00 & -0.220 \\
\hline \multirow[t]{3}{*}{3,200} & 1,500 & 50 & 73.70 & -0.373 \\
\hline & & 70 & 57.42 & -0.360 \\
\hline & & 90 & 39.43 & -0.331 \\
\hline
\end{tabular}

fixed while the polymer concentration was varied, as seen in Table 1. For the second group of tests, the temperature was raised while the polymer concentration was constant, as seen in Table 2. It can be seen that the consistency index $k$ increases with increasing polymer concentration, but decreases with increasing temperature. On the other hand, the flow behavior index $n$ decreases with increasing polymer concentration, and only slightly increases at higher temperature. It can also be observed that polymer concentration affects parameters $k$ and $n$ more than the temperature.

Figure 4 plots the relationship between the parameter $k$ and the polymer concentration $(C \mathrm{p})$. Figure 5 plots the relationship between the parameter $n$ and the polymer concentration $(C \mathrm{p})$. It is clear that the two HPAM products follow similar trends. Because the two products have the same degree of hydrolysis and similar molecular structure, the small difference is possibly due to the difference in molecular weight. The generalized relationships can be expressed as Eqs. 2-4, where $a, b, c$, and $d$ are empirical parameters. Equations 3 and 4 can be used to predict HPAM viscosity at $30{ }^{\circ} \mathrm{C}$, if the polymer concentration is known.

$\ln (k)=a \ln (C \mathrm{p})+b$

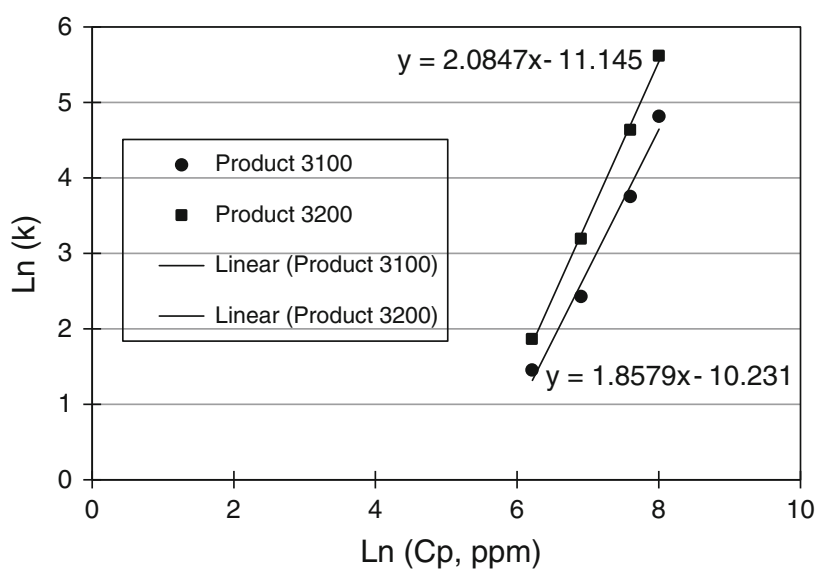

Fig. 4 Relationship between polymer concentration and parameter $k$

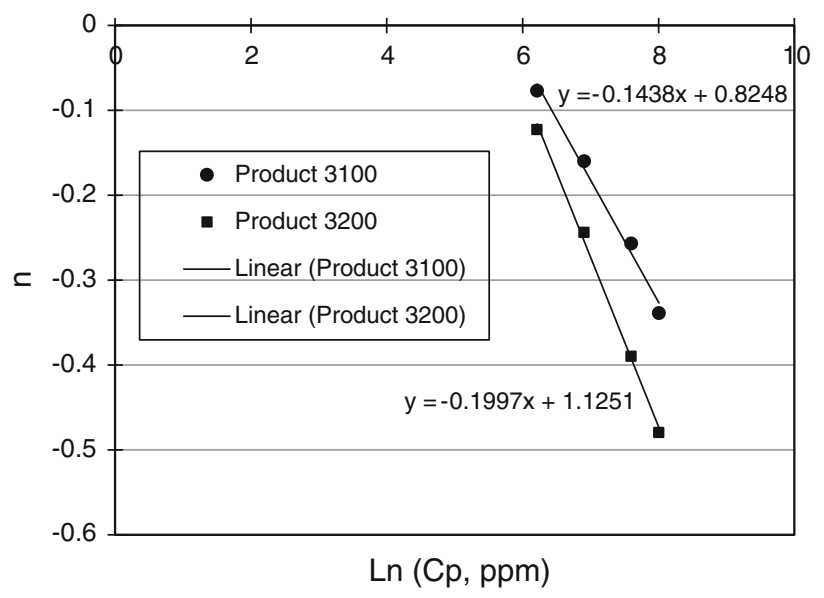

Fig. 5 Relationship between polymer concentration and parameter $n$

or

$k=C \mathrm{p}^{a} e^{b}$

$n=c \ln (C \mathrm{p})+d$

Figure 6 plots the relationship between the parameter $k$ and the test temperature $(T)$. Figure 7 plots the relationship between the parameter $n$ and the test temperature (T). It is clear that the two HPAM products follow similar trend. The small difference is possibly due to their different molecular weights. The generalized relationships can be expressed as Eqs. 5-7, where $e, f, g$ and $h$ are empirical parameters. Equations 6 and 7 can be used to calculate HPAM viscosity at high temperature.

$\log (k)=e T+f$

or

$k=T^{e} \times 10^{f}$ 


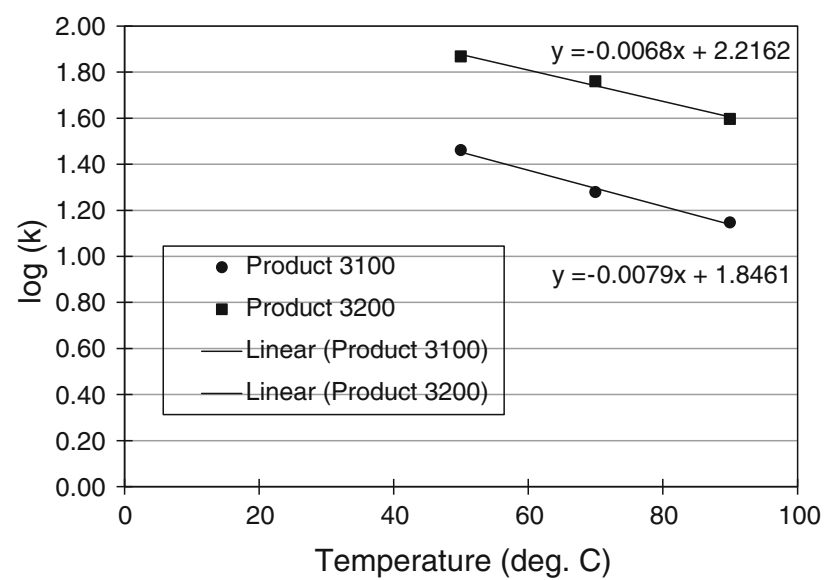

Fig. 6 Relationship between temperature and parameter $k$

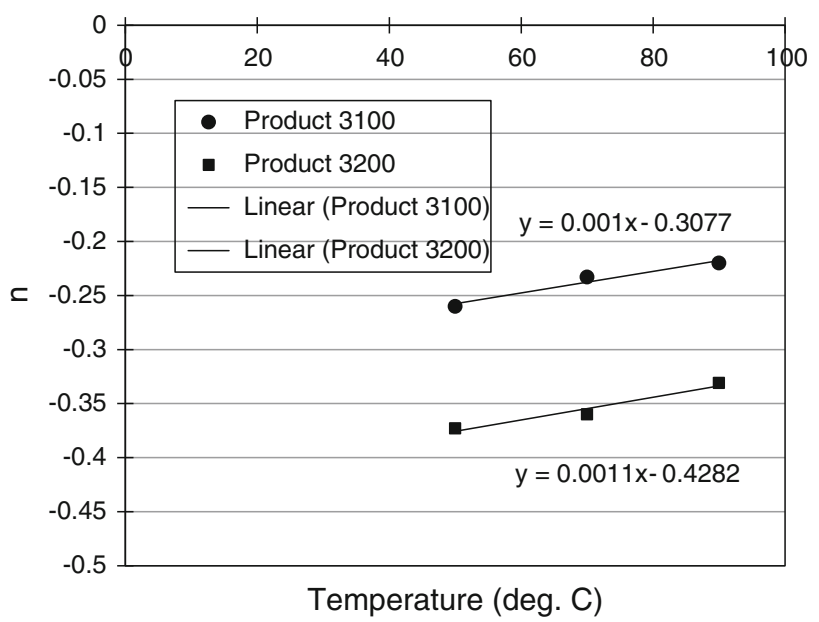

Fig. 7 Relationship between temperature and parameter $n$

$n=g T+h$

The proposed equations are valid for HPAM products. The limitation is that they cannot be used for other polymers. However, HPAM is the only commercial polymer used in polymer flood operations. These equations are therefore considered useful for practical purposes.

\section{Conclusion}

The effects of shearing and thermal degradation on HPAM viscosity are studied in this paper. Experimental results demonstrated that both shearing and heat have negative impacts on HPAM solution viscosity. Simple correlations are established to determine the HPAM solution viscosity at a wide range of shearing rates and temperatures up to $90{ }^{\circ} \mathrm{C}$. In the future, other factors such as salinity should also be investigated.

Open Access This article is distributed under the terms of the Creative Commons Attribution License which permits any use, distribution, and reproduction in any medium, provided the original author(s) and the source are credited.

\section{References}

Chen T, Song Z, Fan Y (1998) A pilot test of polymer flooding in an elevated-temperature reservoir. SPE Reserv Eval Eng 1(1):24-29

Gao C (2011) Scientific research and field applications of polymer flood in heavy oil recovery. J Petrol Explor Prod Technol 1(2):65-70

Littmann W (1988) Polymer flooding 3:2-4

Maerker JM (1975) Shear degradation of partially hydrolyzed polyacrylamide. SPE J 15(4):311-322

Mungan H (1972) Shear viscosity of ionic polyacrylamide solutions. SPE J 12(6):469-473

Needham R, Doe P (1987) Polymer flooding review. J Petrol Technol 39(12):1503-1507

Rabia H (1985) Oilwell drilling engineering: principles and practice, Graham \& Trotman 96-98

Ryles RJ (1988) Chemical stability limits of water soluble polymers used in oil recovery processes. SPE Reserv Eng J 3(1):23-34

Seright RS, Fan T, Wavrik K (2011) New insights into polymer rheology in porous media. SPE J 16(1):35-42

Sheng J (2010) Modern chemical enhanced oil recovery, Gulf Professional Publishing 101-103

Wang D, Dong H, Lv C, Fu X, Nie J (2009) Review of practical experience by polymer flooding at Daqing. SPE Reserv Eval Eng 12(3):470-476

Ward JS, Martin FD (1981) Prediction of viscosity for Partially Hydrolyzed Polyacrylamide solutions in the presence of Calcium and Magnesium ions. SPE J 21(5):623-631 